\title{
BADERNEIROS, ARRUACEIROS, GUERRILHEIROS: UM ACONTECIMENTO NA TRANSIÇÃO DEMOCRÁTICA
}

Rioters, rowdies, guerrilla fighters: an event in the democratic transition

Agitadores, alborotadores, guerrilleros: un acontecimiento en la transición democrática

\section{DANIEL BARBOSA ANDRADE DE FARIA}

Universidade de Brasília/UnB - Departamento de História, Brasília - DF, Brasil

Possui graduação em História pela Universidade de Brasília (1998), mestrado em História pela Universidade de Brasília (2000) e doutorado em História pela Universidade Estadual de Campinas (2004). Concluiu o pós-doutorado pela mesma universidade em 2008. Atualmente é professor Adjunto I do Departamento de História da Universidade de Brasília (krmazov@hotmail.com) 


\section{RESUMO}

Recentemente, o acervo da Secretaria de Segurança Pública do Distrito Federal relativo à ditadura militar foi aberto ao público. Um dossiê sobre o "badernaço" (tumulto acontecido depois da manifestação contra o Plano Cruzado II) é parte desse acervo. Trata-se da documentação da Comissão de Sindicância instaurada para apurar denúncias de que o "badernaço" ocorrera com conivência ou cooperação de setores do Governo, como a Secretaria de Segurança Pública ou a chamada "comunidade de informações". Este artigo faz uma análise desse dossiê, a partir dos temas da "transição democrática" e das sobrevivências da ditadura militar (aqui entendidas, conceitualmente, nos termos do fantasmagórico, espectral).

PALAVRAS-CHAVE: Transição democrática; Manifestações políticas; Ditadura militar.

\section{ABSTRACT}

Recently, the archives of the Brazilian Federal District's Department of Public Safety regarding the Military Dictatorship was open to the public. A dossier on the "badernaço" (a riot that happened after a demonstration of Plano Cruzado II) is part of these archives. It is the documentation of the commission of inquiry that was established to the allegations that the "badernaço" occurred with the collusion or cooperation of sectors of the government, such as the Public Safety Department or the so-called "information community". This article analyzes this dossier from the perspective of the topics of the "democratic transition" and the survivals of the Military Dictatorship (which are understood, conceptually, in terms of the ghostly, spectral).

KeYWORDS: Democratic transition; Political demonstrations; Military dictatorship.

\section{RESUMEN}

Recientemente, el acervo de la Secretaría de Seguridad Pública del Distrito Federal relativo a la Dictadura Militar fue abierto al público. Un dossier sobre el "badernaço" (tumulto ocurrido después de una manifestación contra el "Plano Cruzado $\|^{\prime \prime}$ ) es parte de ese acervo. Se trata de la documentación de la comisión de investigación instaurada para averiguar denuncias de que el "badernaço" ocurrió con connivencia o cooperación de sectores del gobierno, como la Secretaría de Seguridad Pública o la llamada "comunidad de informaciones". Este artículo hace un análisis de ese dossier, a partir de los temas de la "transición democrática" y de las supervivencias de la Dictadura Militar (aquí entendidas, conceptualmente, en los términos de lo fantasmagórico, espectral).

PALABRAS-ClAVE: Transición democrática; Manifestaciones políticas; Dictadura militar. 


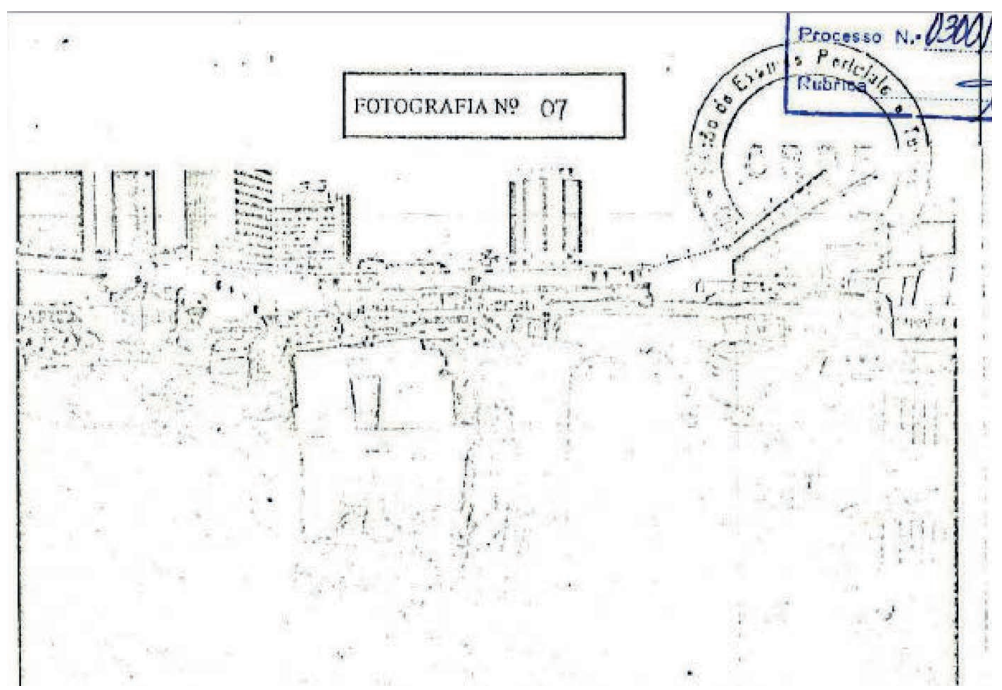

Ao cair da tarde, dois desconhecidos se encontram nos corredores escuros de uma galeria de quadros. Com um leve calafrio, um deles diz: - Este lugar é sinistro. Você acredita em fantasmas?

- Eu não, respondeu o outro. - E você? - Eu, sim - disse o primeiro, e desapareceu. George Loring Frost (Borges; Ocampo; Bioy Casares, 2013: 186).

ecentemente, o acervo da Secretaria de Segurança Pública do Distrito Federal relativo
ao período da ditadura militar foi aberto ao público. A publicização desse acervo remete às relações entre justiça, direitos humanos e democracia, podendo ser pensada como mais um momento no percurso da redemocratização - que inclui os aspectos do direito à informação e à memória. Nesse acervo, em meio a informes e relatórios trocados entre órgãos de repressão e espionagem política, há um extenso documento sobre o evento que ficou conhecido como "badernaço", ocorrido em Brasília, em novembro de 1986 - um tumulto que tomou conta da Esplanada dos Ministérios depois de manifestação contra o Plano Cruzado II. No caso, trata-se do relatório final, das atas e do material colhido para as apurações realizadas por Comissão de Sindicância nomeada pelo então governador José Aparecido. A comissão foi criada porque, já num primeiro momento, surgiram denúncias na imprensa e nos meios políticos de que as depredações e incêndios de viaturas policiais teriam sido feitas por infiltrados na manifestação, talvez mesmo policiais ou agentes ligados à "comunidade de informações" - tudo isso, diante de uma ação policial dividida em duas fases: num primeiro momento, repressão violenta contra a manifestação; no momento dos tumultos, passividade e contemplação do espetáculo. 
Inicialmente, podem ser destacados alguns aspectos que dão a essa documentação um sentido enigmático - que, por sua vez, repercute os embaraços da assim chamada "transição democrática", tanto em sua relação aos fantasmas do passado ditatorial que não pararam de assombrá-la quanto em relação ao seu futuro, de uma transição lentíssima, instável e incerta para uma democracia que parece sempre sumir no horizonte.

Em primeiro lugar, o acervo só veio a público em 2017 - foi transferido para o Arquivo Público do Distrito Federal em 1995. Nos diários de campo, referentes a essa transferência de 1995, lê-se que a documentação gerada pelas Forças Armadas, pela Polícia e pelo Corpo de Bombeiros seria avaliada por comissões compostas por membros de cada órgão. Trata-se, evidentemente, de documentação valiosa, mas desfalcada. As lacunas são óbvias - por exemplo, os documentos do período mais violento da repressão, entre 1968 e 1974, são justamente os ausentes. Além disso, como habitualmente ocorre com esse tipo de acervo, os documentos fazem referências a outros documentos que não são encontrados.

A natureza dos informes e a circulação entre diferentes órgãos, como CENIMAR, CISAe Polícia Federal, transmite uma ideia aproximada da intensidade e das atividades desse aparato, no que se refere ao Distrito Federal. Contudo, quão distante é essa "proximidade", conjecturada a partir das lacunas, daquilo que efetivamente se deu na atuação da Secretaria de Segurança Pública durante a ditadura militar é questão em aberto. 0 fato de as próprias instâncias produtoras desses documentos e, possivelmente, mesmo de agentes envolvidos em violações aos direitos humanos e em crimes contra a sociedade serem os primeiros responsáveis pela avaliação de seu valor histórico remete à estranheza e aos percalços da chamada "transição democrática" no Brasil - seus limites incertos, e tão debatidos pela historiografia, entre abertura, transição, redemocratização, conquista social, cidadania, tutela etc. (Castro; D’Araújo, 2001; Silva, 2007).

No que se refere ao dossiê sobre o "badernaço", há uma nota escrita à mão: "esta documentação estava localizada na sala climatizada, não podendo, contudo, atestar sua procedência"1. A comissão de sindicância, designada pelo Decreto n. 9.971, de 1 de dezembro de 1986, tinha como objetivo apurar as responsabilidades dos tumultos ocorridos em Brasília no dia 27 de novembro de 1986. Dela, faziam parte Humberto Gomes de Barros, procurador geral do Governo do Distrito Federal; José Olavo de Castro, secretário de Segurança Pública do Distrito Federal; Cristovam Buarque, reitor da Universidade de Brasília; Carlos Marx Torres, presidente do Sindicato dos Jornalistas do Distrito Federal; Sebastião Rios Correa, presidente da Comissão de Justiça e Paz; José Neves, presidente da Federação dos Comerciários do Distrito Federal; e Lindberg Aziz Cury, presidente da Associação Comercial do Distrito Federal. Os efeitos concretos esperados dos resultados das apurações ainda 
são nebulosos. Seria a comissão uma mera resposta protocolar do Governo a um clima de suspeitas, espetáculo público previamente destinado ao fracasso, ou uma comissão com poder efetivo para a apuração dos fatos?

A comissão de sindicância era uma mescla entre representantes da sociedade civil e dos próprios agentes do Estado então sob suspeita, como o secretário de Segurança Pública. Aliás, entre os órgãos convidados para colaborar com os trabalhos da comissão, estava o Serviço Nacional de Informações, então presidido pelo general Ivan de Souza Mendes. ${ }^{2}$ Talvez se possa pensar que não poderia ser diferente em 1986 - e parece ser assim mesmo. A constituição vigente, vale lembrar o óbvio, ainda era a de 1967, portanto, o aparelho policial era uma das sobrevivências da ditadura militar. Como seria possível uma investigação sem a participação dessas instituições? 0 "não poderia ser diferente", porém, não pode nos levar a não pensar sobre o sinistro da situação - até porque ela tem ressonâncias com outros eventos que marcaram a transição, como o atentado do Riocentro ou os percalços de familiares, ativistas e comissões oficiais quando o assunto é investigar crimes de Estado (Green; Ward, 2004) cometidos durante a ditadura militar.

0 decreto de criação da comissão era carregado de ambivalências. ${ }^{3}$ As considerações preliminares tratavam do "repúdio do Governo e da Sociedade, aos acontecimentos verificados em Brasília, no Dia Nacional de Ação de Graças"; remetiam ao "dever democrático de apuração, no menor prazo possível, das ocorrências de extrema gravidade"; sugeriam que a tarefa da comissão era sanar "dúvidas levantadas por instituições e pela imprensa, quanto aos responsáveis pelos atos criminosos perpetrados na ocasião". 0 decreto se referia ainda ao fato de que as forças policiais eram imputadas de violência e que havia uma "obrigação moral do Governo do Distrito Federal de esclarecer os fatos". O Governo, então sob suspeita de instigar o "badernaço", seja pela ação de agentes infiltrados, seja pela complacência da Polícia Militar, criava uma Comissão de Sindicância dotada de poderes indefinidos, com 0 objetivo de dar uma resposta definitiva para (ou contra) a suspeita.

A questão da democracia, apontada como um dever cívico de apuração dos fatos, estava no centro dessas ambivalências e tensões. Afinal, o tema da Nova Constituição pairava no ar, bem como as discussões sobre o passado ditatorial, seus crimes não resolvidos e seus desaparecimentos forçados - e, ainda, a sobrevivência e destino de dispositivos estatais montados durante a ditadura militar e durante a redemocratização (Joffily, 2004). Quem eram então os "baderneiros" que irromperam na Esplanada dos Ministérios, depredando prédios e queimando carros? Quem eram esses que punham em risco a própria existência de uma política democrática? Quem, afinal de contas, recusava a democracia? Como veremos, tanto no decreto que institui quanto nas apurações e no relatório final da comissão de sindicância, essa seria a questão central em torno do "badernaço". 


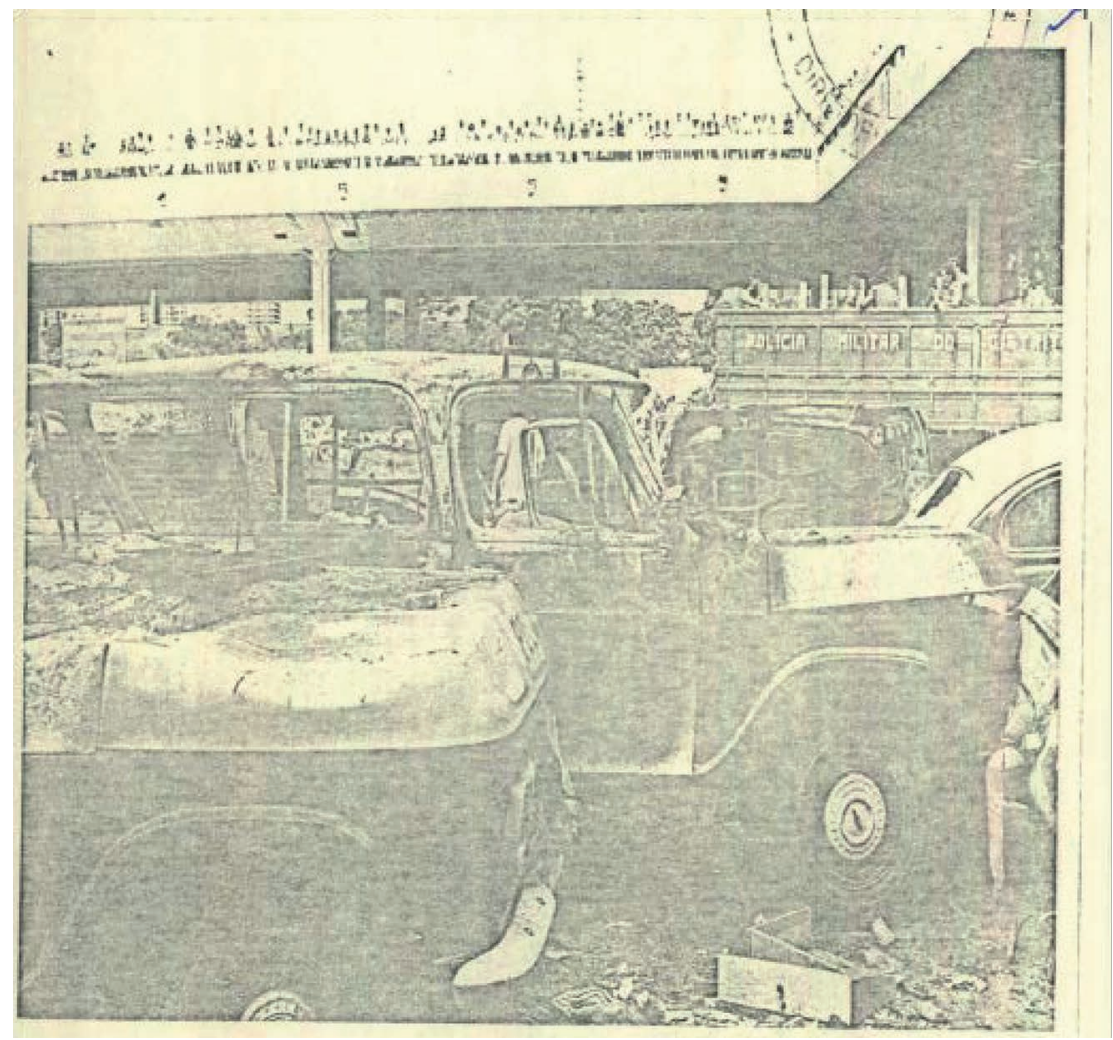

\section{O "BADERNAÇO”: PRIMEIRAS LEITURAS}

D e acordo com a matéria "Secretário admite erro na repressão ao grande badernaço", 4 Olavo de Castro, então na Secretaria de Segurança Pública do Distrito Federal - bem como membro da comissão de sindicância criada pelo governador José Aparecido - reconheceu que houve falha na ação da Polícia Militar, diante dos tumultos que resultaram no incêndio de quatro agências bancárias e 20 veículos militares - isso diante do contraste de que, no que se referia aos incendiários, nenhum fora preso em flagrante. As 34 prisões que se deram naquele momento ocorreram durante a fase pacífica da manifestação. Por outro lado, fotografias mostravam depredadores atuando diante da observação inerte de policiais.

0 reconhecimento da falha passava, porém, pela justificativa de que os "agitadores" eram de "alta categoria". Mais ainda, agitadores que "demonstraram ser altamente capazes, promovendo uma ação de manual de guerrilha urbana". Os manifestantes "desapareciam e apareciam num outo lugar", de acordo com o secretário. Guerrilha urbana, ações clandestinas de militantes espectrais dotados dos poderes da invisibilidade e do teletransporte, manuais 
da guerra revolucionária - tudo isso sobrevivendo em 1986, numa mistura em que "fantasmas" do passado (a luta armada, a guerra revolucionária) embaralhavam-se a figuras do horror científico da "década perdida" (o filme A mosca é de 1986), ao menos nas palavras do secretário de Segurança. 0 que, no mínimo, sugere sobrevivências de tensões da ditadura militar, interferindo nos debates políticos e no imaginário da povo naquele momento de redemocratização.

Por outro lado, tomemos a avaliação do jornalista Villas-Bôas Corrêa, que havia décadas era repórter e analista político. Em artigo intitulado "A transição fardou-se", 5 Villas-Bôas notara que o lobby das Forças Armadas na Constituinte teria obtido sucesso em todas as suas pretensões. Entre elas, uma central, e que sempre retorna sob o espectro da "intervenção militar": a questão da definição constitucional do papel das Forças Armadas. 0 jornalista falara mesmo em "tutela da transição". Ao menos no que se refere à interferência militar na Assembleia Constituinte, com a consequente permanência de dispositivos derivados da ditadura, a leitura de Villas-Bôas não perdeu a atualidade (Zaverucha, 2010). A questão da tutela, como já foi observado anteriormente, é tema de debate historiográfico. Por outro lado, ainda no calor do momento, Villas-Bôas identificara o "badernaço" como o momento de virada na redemocratização. Até então, segundo o jornalista, os militares teriam observado a "Nova República" com certa distância. Então:

O badernaço de Brasília, assinalando o primeiro desmaio da autoridade civil e a estreia da insubordinação social contra o governo, também registra a volta dos militares, o seu retorno ao processo. Convocados, aplaudidos, mas presentes, respondendo à chamada. De lá para cá, a qualquer pretexto e até sem pretexto algum, os militares foram se investindo na tutela da transição.

A tese de Villas-Bôas, evidentemente, não pode simplesmente ser adotada como explicação histórica, leitura não mediada de uma crônica política escrita com outra finalidade (menos entender o "badernaço" do que criticar os aspectos militares do processo constituinte). Não se trata de concluir que o "badernaço" fora o evento central da transição democrática, o momento que definiu seus limites e as margens de sua instabilidade. Em primeiro lugar, porque não se pode afirmar que antes de 1986 os militares assistiam passivamente aos acontecimentos políticos. Em segundo lugar, porque, do ponto de vista teórico, uma explicação baseada numa relação linear de causa e efeito tende a ser insatisfatória. De qualquer modo, é importante observar a força do evento na percepção de um dos analistas políticos mais constantes da História do Brasil ao longo do século XX. Além disso, retirada a ideia de causalidade entre "badernaço" e "tutela militar", resta a percepção de que um evento como o do "badernaço" minara um dos aspectos centrais da "transição democrática" - justamente a que dizia respei- 
to à passagem do poder das mãos dos militares para a sociedade civil. Ou seja: não se trata aqui de se decidir o estatuto do "badernaço" como causa de outros eventos na História da redemocratização, mas sim de pensar sobre o sentido simbólico do acontecimento que remeta ao tema dos limites e das possibilidades da redemocratização no Brasil. Pensando o acontecimento como "um pedaço de tempo e de ação posta em pedaços", isto é, não um dado em si mesmo, mas um evento que irrompe com a marca do heterogêneo, inseparável do modo como ele é transmitido, comentado (Farge, 2011: 71).

\section{"HORDAS DE BÁRBAROS" NA TRANSIÇÃO DEMOCRÁTICA}

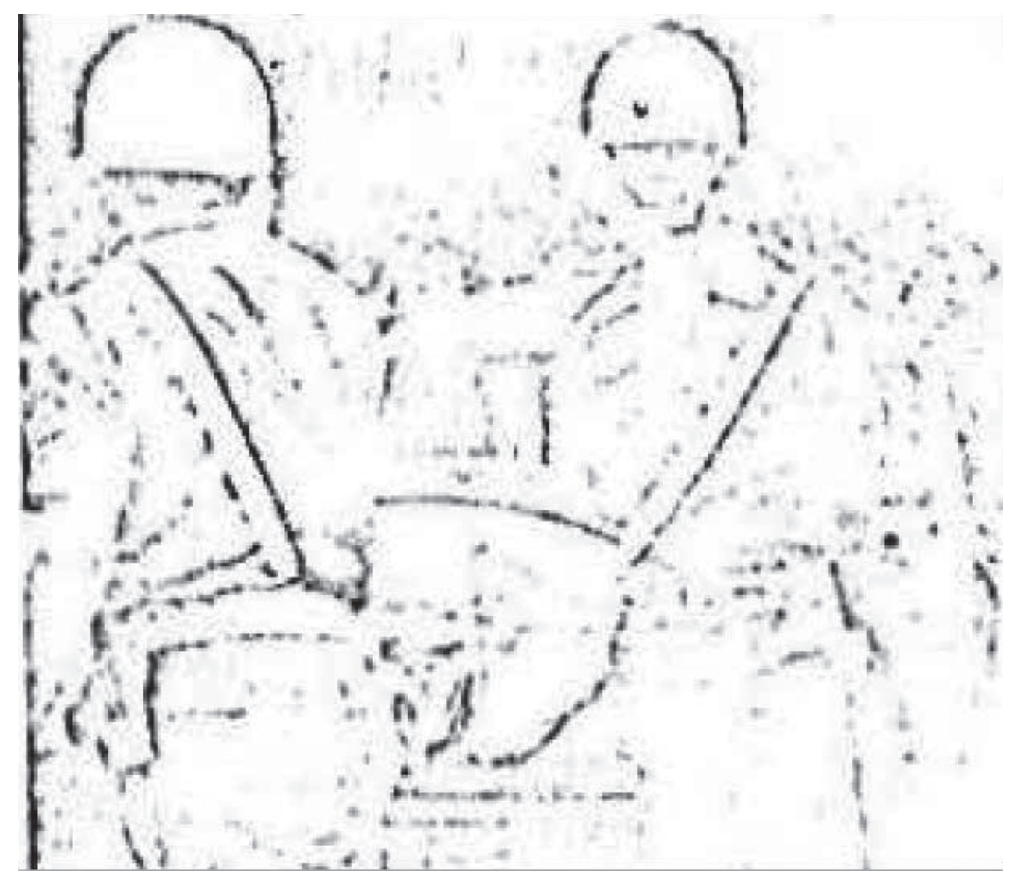

$\mathrm{N}$ ão se pretende, no âmbito deste artigo, discutir o contexto específico da manifestação que se tornou conhecida como "badernaço" (ou seja, o governo Sarney, o Plano Cruzado e suas reviravoltas etc.). Antes, trata-se de pensar sobre alguns signos associados à baderna política, aos tumultos e a sua repercussão na chamada "transição democrática". 0 que implica a postulação de algumas questões mais gerais. Note-se, por exemplo, que uma cronologia quase consensual situa o início da dita transição no processo de "abertura" iniciado em 1974, com Geisel. 0 marco final da ditadura militar oscila entre o fim do Al-5, em 
1979, a eleição indireta de 1985 e a promulgação da Constituição de 1988 (Quadrat, 2014). Cronologia que fica ainda mais complicada quando se pensa nas sobrevivências da ditadura militar, em seus aspectos institucionais, em termos jurídicos relativos à apuração dos crimes de Estado e à inacabada e presente "guerra das memórias" (Martins Filho, 2002).

Por outro lado, a questão não pode ser pensada em termos exclusivamente nacionais, é preciso atentar para os significados da transição democrática, tendo em vista seus alcances internacionais e mesmo globais. Em obra interessantíssima para discutir a questão, o historiador Nicolas Guilhot (2005) levanta inúmeras discussões relativas a esses temas nas décadas de 1980 e 1990, algumas das quais aqui destacaremos. Em primeiro lugar, é preciso estar atento ao dado de que, entre o fim dos anos 1970 e 1980, os Direitos Humanos e a democracia se tornaram uma linguagem da "governança global". Com a institucionalização crescente de redes de intelectuais, acadêmicos e organizações governamentais e não governamentais forma-se uma profissionalização de supostos especialistas em democracia, assessores dedicados ao assunto das reformas de Estados autoritários, financiados por fundações privadas e oficiais.

Nessa rede heterogênea de ativistas, acadêmicos e instituições governamentais, montada em torno de um suposto consenso democrático internacional, era o significado mesmo de conceitos como democracia e direitos humanos que estavam em pauta: quem são os representantes legítimos dos direitos humanos e da democracia? Os direitos limitam-se a civis e políticos ou incluem direitos sociais? A democracia é uma questão de eleições livres e transparentes ou uma forma pacífica de resolver conflitos?

0 autor também apresenta questões interessantes sobre a América Latina e suas transições democráticas (Guilhot, 2005: 96-97). Muitos dos ativistas e intelectuais mais ativos nessa rede global de democracia e direitos humanos tinham combatido ditaduras de direita apoiadas pelos Estados Unidos - alguns, como Bolívar Lamounier, vinculados a institutos como o National Endowment for Democracy, criado durante a administração Reagan. Houve, assim, nos anos 1980, uma proliferação de encontros acadêmicos e publicações sobre a transição democrática, nos quais podemos ver a constituição e as interações dessa rede internacional, que inclui ainda intelectuais como Adam Przeworski, Guillermo O'Donnel e Fernando Henrique Cardoso.

Daí, mesmo não se tratando de uma rede homogênea, tanto em termos políticos quanto intelectuais, a construção de alguns lugares-comuns que marcam essa bibliografia específica, a começar pelo próprio conceito articulador de "transição" (Guilhot, 2005: 146): uma transição, antes de tudo, nega as ideias de ruptura, de revolução. A transição democrática fora pensada como algo a ser feito, mediante negociações, de dentro do próprio aparelho de Estado 
ditatorial, tratando-se, portanto, de uma espécie de concerto palaciano entre os agentes de um regime autoritário propensos à abertura e os defensores da democracia avessos a propostas consideradas radicais. Enfim, o que emerge nesse contexto é a ideia de uma democracia de baixa intensidade (Guilhot, 2005: 152).

"Baixa intensidade", ou, em conceito semelhante, defendido por Bolívar Lamounier, uma "democracia mitigada", em que, no exemplo dado pelo cientista político, mesmo com a proibição da existência do Partido Comunista, houvesse um espaço para a livre discussão sobre a possibilidade de sua legalização - o que, ainda de acordo com Lamounier, abriria um horizonte de democratização progressiva com "absorção parcial de ressentimentos" (Lamounier e Faria, 1981: 56-57).

As "hordas de bárbaros", os radicais, os ressentidos com o passado e os renitentes da linha dura seriam, assim, os maiores empecilhos para a consolidação da democracia dentro do horizonte desse campo discursivo. Privilegiava-se as virtudes da moderação, as habilidades na negociação entre representantes de uma paradoxal "aristocracia democrática" - o centro, talvez mesmo o "centrão", em detrimento dos radicalismos dos "dois lados", esquerda e direita. 0 consenso, ${ }^{6}$ note-se porém, fundava-se em torno de uma lógica, de uma forma de se pensar a política. Não se estabelecia, de saída, quem seriam os atores qualificados para figurar nessa função de moderação e de governança da transição democrática. Por isso, é nesses termos de uma forma de se pensar, que encontramos aproximações (em outros aspectos, paradoxais) entre os discursos da abertura lenta e gradual e da transição democrática.

Para Golbery do Couto e Silva, esse exercício da moderação centrava-se nos próprios agentes estratégicos da ditadura militar. Num texto apresentado em conferência na Escola Superior de Guerra que marcou época (Couto e Silva, 1981), Golbery comparou a abertura política com os movimentos de sístole e diástole do coração, não só recobrindo a História política sob uma metáfora naturalizada, remetendo-a a um processo orgânico, mas também apontando para uma dimensão sensível e mesmo potencialmente mortal da gestão governamental - afinal, o "coração do Estado" estava sujeito a "arritmias, isquemias e enfartes" (Couto e Silva, 1981: 21). Daí a tese da necessidade de que os governantes imprimissem um ritmo ordenado entre centralização e descentralização do Estado, tendo em vista a consolidação democrática da sociedade brasileira.

Para o colapso civilizacional, os riscos residiriam nos excessos. No caso da ditadura militar, teríamos um momento de sístole no "coração do Estado". Então, a centralização crescente acabara gerando uma máquina estatal excessiva, complexa, que se retroalimentava, absorvendo as energias da sociedade, tornando-se, no "extremo final" que Golbery não nomeara 
explicitamente (estaria se referindo ao DOI-CODI, ao SNI e à sua monstruosidade ou ao colapso econômico daqueles anos?), semelhante aos "black holes detectados pela astronomia moderna e dos quais nenhuma luz consegue escapar" (Couto e Silva, 1981: 24). Golbery advertira ainda que uma leitura equivocada da oposição entre direita e esquerda poderia levar a erros na condução da abertura. A leitura equivocada se basearia na imagem de uma linha em que os extremos da esquerda e da direita tornam-se cada vez mais afastados. A imagem correta, para Golbery, seria semelhante a uma ferradura, em que a extrema-esquerda e a extrema-direita não se afastavam, aproximavam-se, criando mesmo uma espécie de "aliança tática" (Couto e Silva, 1981: 26-27). Caberia, então, ao governante responsável pela abertura, o trabalho de manobra política entre esses extremos, preservando o centro da ferradura como eixo de articulação.

\section{TRANSIÇÃO DEMOCRÁTICA, TEMPO DE ESPECTROS}

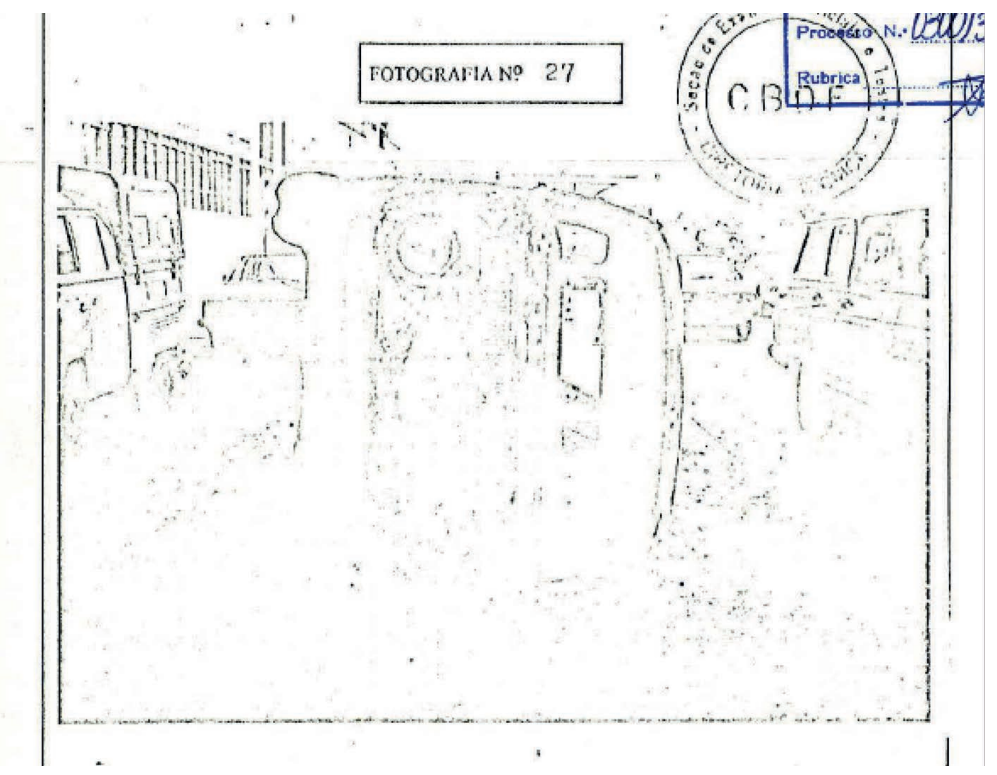

á no fim da década de 1980, uma daquelas várias publicações voltadas para o tema da transição democrática publicadas dentro e fora do Brasil, fazia um balanço melancólico. Adam Przeworski, cientista político e professor da Universidade de Chicago, abria seu artigo com a ideia de que a transição brasileira parecia interrompida, entre um autoritarismo que não mais existia e uma democracia não instalada (PRZEWORSKI, 1989: 19). A imagem por ele 
proposta, entre pueril e fantasmagórica, era a de uma bola de pinball paralisada, depois de ter sido lançada - quando o esperado seria que a bola percorresse seu caminho naturalmente, ao longo do jogo de fliperama, descendo pelo plano inclinado, aparecendo e desaparecendo.

Já vimos no texto de autoria de Golbery a imagem de um coração em trabalho constante contra a morte. No livro aqui citado, são recorrentes as ideias e imagens relacionadas à agonia, à incerteza, à instabilidade. Mais recentemente, e em espectro ideológico bem distinto, um livro recebeu o título de "o que resta da ditadura" - a ideia de "resto" aqui deve ser pensada não como uma sobra irrelevante, e, sim, como um resíduo, mesmo como um resíduo radioativo, com sua capacidade de contaminar um ambiente por séculos, tendendo ao infinito (1986 foi 0 ano do acidente de Chernobyl).

Não somente o fim da ditadura militar, mas o fim da Guerra Fria vem sendo assombrado por esses aspectos fantasmagóricos de um passado que, paradoxalmente, ainda sobrevive - com um potencial traumático para o futuro, pois esse passado sempre está prestes a retornar. Diante disso e a partir do livro Espectros de Marx (Derrida, 1994), há, inclusive, uma proposta de uma "virada espectral" nas ciências humanas - por comparação com a chamada "virada linguística" (Blaco \& Peeren, 2013). Exageros e pretensões programáticas à parte, os conceitos e imagens em torno do espectral têm grande potencial interpretativo para a História que envolve a abertura, lenta e gradual, e a transição democrática inacabada - ou mesmo o retorno do passado que parecia passado (como no caso das defesas recentes de uma nova "intervenção militar").

A ideia do espectral, do fantasmático, é interessante por sugerir que as relações entre passado, presente e futuro não são simplesmente lineares. Aspectos do passado sobrevivem no presente como resíduos ativos, apontando para uma dimensão da História que não se dá como progresso e sim como trauma e repetição. Ela sugere, ainda, a ideia de uma presença latente, imaterial e, ao mesmo tempo, real. Por fim, o espectral contemporâneo tem relação com a dimensão midiática da realidade. Fotografias, vídeos e tantos outros aparatos fazem com que o cotidiano seja povoado de imagens, compondo um espaço público demarcado pela audiovisualidade (Mauad, 2016).

As imagens usadas neste artigo são todas do dossiê sobre o "badernaço". Trata-se de fotografias feitas por integrantes do Corpo de Bombeiros após o evento, voltadas para a produção de laudos técnicos sobre os incêndios ocorridos. As fotografias foram reproduzidas para a Comissão de Sindicância (que, aparentemente, não as usou efetivamente em sua apuração). Nos processos de reprodução das imagens, de realização de cópias sobre cópias, elas perderam as cores dos originais e depois se reduziram aos contornos, às linhas, onde entrevemos a Esplanada dos Ministérios, uniformes de policiais, silhuetas de transeuntes, entre outros. Elas 
não estão cumprindo, neste artigo, uma função meramente ilustrativa. Mais do que quaisquer palavras, é nessas imagens que percebemos o sentido espectral do "badernaço" e de eventos semelhantes, que pesam como uma sombra na História da democracia.

\section{BADERNEIROS, ARRUACEIROS, GUERRILHEIROS OU: QUEM NÃO QUER A DEMOCRACIA?}

compostos de baderneiros, aruaceifosiros, parecendo ao declarante

Dia de Ação de Graças. Segundo matéria da revista Veja, datada de 3 de dezembro de 1986, incluída no dossiê da comissão de sindicância sobre o "badernaço", um "vendaval agita Brasília". ${ }^{7}$ Cerca de cinco mil pessoas participavam do que seria, até então, a maior manifestação "dessa natureza" registrada na Esplanada dos Ministérios. Brasília teria se tornado uma "praça de guerra" no "primeiro quebra-quebra do novo regime civil". Na hora da manifestação, o presidente José Sarney estava na catedral de Brasília, tendo de ser escoltado pelo Exército para percorrer o caminho que leva desta ao Palácio do Planalto. A catedral estava cercada por um aparato policial-militar - a manifestação acontecia em outro lugar, em frente ao Ministério da Fazenda. Estranhamente, dali, os manifestantes foram empurrados pela polícia, com o uso de gás lacrimogêneo, em direção à estação rodoviária. Na rodoviária, finalmente, alguns mascarados presentes na manifestação começaram os atos de depredação. Dezenas de viaturas policiais e militares estavam paradas no estacionamento, sem proteção nenhuma. Elas foram incendiadas ao longo de um tumulto que teria durado entre uma e duas horas.

Baderneiros, mascarados, guerrilheiros - ou policiais infiltrados, talvez agentes da chamada "linha-dura" que vinha, desde os anos 1970, tentando sabotar a abertura e, depois, a transição democrática. Quem, afinal de contas, não queria a democracia? E por que, de tempos em tempos, a imagem da paralisia, do colapso, retornava e retorna sob as figuras de golpe, de intervenção militar? Estamos aqui diante de um tempo que não se configura pelo movimento implícito na própria ideia de transição de um estado a outro. Ao contrário, figuras associadas a um passado delimitado no tempo retornam muitas vezes sentidas, como um anacronismo.

A criação da comissão de sindicância, em 1986, já vinha imersa em uma dinâmica de assombrações e sobrevivências do passado ditatorial. 0 próprio secretário de Segurança trouxe à tona os fantasmas da esquerda armada, da guerrilha urbana. Quanto aos crimes de Estado e seus agentes, depois de casos como o do Riocentro e de outros atentados terroristas em meio aos sucessos e fracassos da "transição", em que medida se podia e se pode acreditar que 0 "buraco negro", na expressão de Golbery, do governo centralizado e monstruoso é, de fato, 
algo exterior à própria máquina estatal? Se mesmo da parte de próceres da abertura, como Golbery, haveria a ideia de isolar a chamada "linha-dura", por que, então, seus crimes continuam acobertados, depois de inúmeros governos, ao ponto mesmo de poderem sobreviver impunes ao que pode vir a ser o ocaso da "Nova República"?

A comissão de sindicância de 1986 perguntou insistentemente aos depoentes (policiais, sindicalistas e jornalistas): quem eram os baderneiros? Quem transformou uma manifestação pacífica num festival de carros incendiados? Indícios fortes apontavam para a participação de agentes provocadores - talvez mesmo da Polícia Militar de Goiás. As viaturas policiais foram enfileiradas e simplesmente abandonadas na Esplanada, como uma espécie de isca para manifestantes revoltados ou para os provocadores poderem atuar. Os incendiários não foram reconhecidos individualmente. Pareciam jovens, fortes; não eram conhecidos militantes políticos de Brasília. Durante o tumulto, policiais impediam jornalistas de fotografar o evento - alguns tiveram suas câmeras tomadas e destruídas.

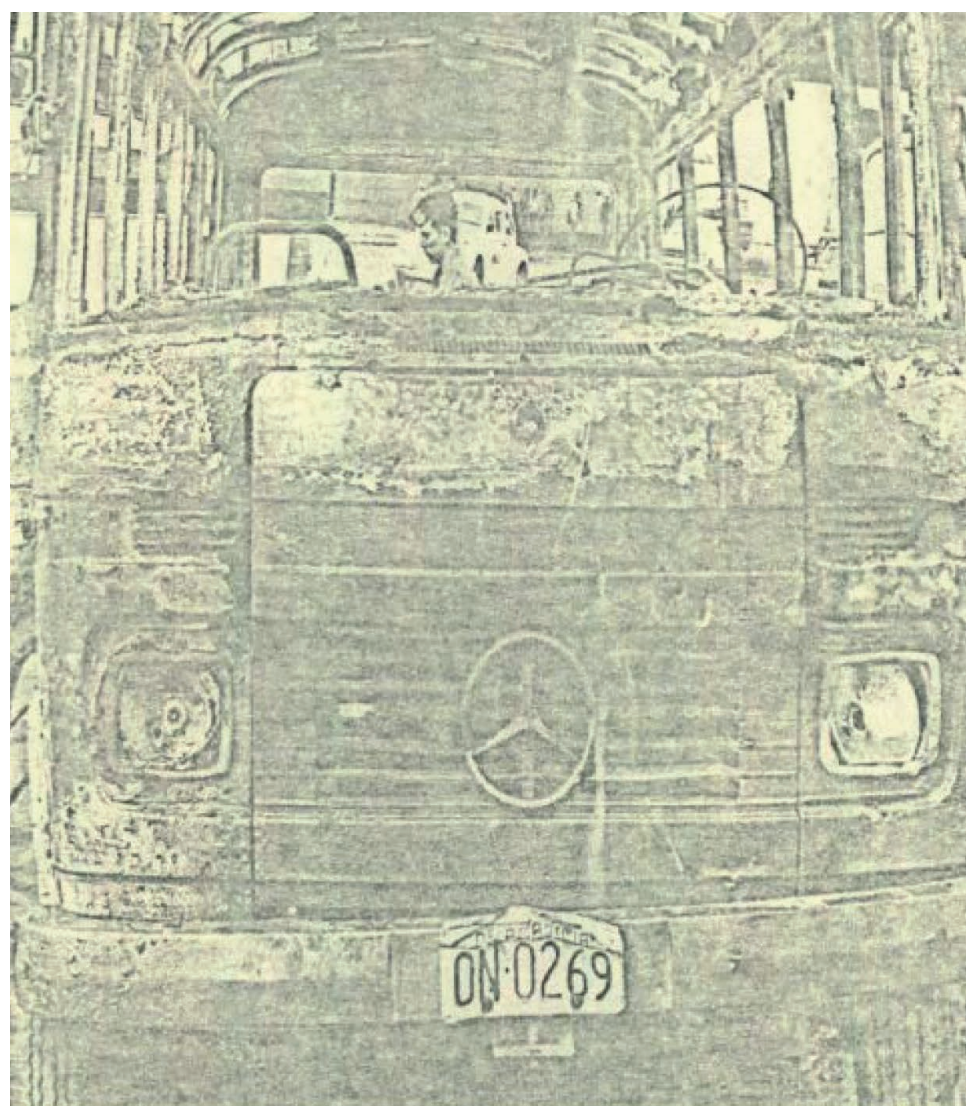


Em depoimento, o Major Túlio Cabral Moreira, subcomandante do Batalhão de Guardas da Polícia Militar do Distrito Federal, registrava que:

Grande número dos manifestantes que depredaram e incendiaram as viaturas era composto de elementos jovens, tendo como característica parte do rosto coberto com camiseta; que o declarante não conseguiu identificar, com sua experiência de policial, os depredadores entre pessoas que já tivessem passagem pelas delegacias onde serviu; que os depredadores, embora na maioria jovens, não pareciam obedecer a um comando, mais parecendo que agiam cada um por conta própria; que não havia, digo, o declarante não notou qualquer característica, quer na indumentária, quer nos gestos, que diferenciasse os depredadores do comum das pessoas; que não pode afirmar que os manifestantes já vinham com a decisão de queimar os veículos, mas pela rapidez com que agiram até parece que era assim. ${ }^{8}$

Já o coronel Hugo Guimarães Costa teria iniciado suas declarações dizendo que, desde 1959, fazia parte da Polícia do Distrito Federal, e que, nessa condição, "acompanhou todos os movimentos estudantis, operários e quaisquer reivindicações no Distrito Federal". ${ }^{9}$ Mesmo assim, dizia ter dificuldade de caracterizar se, no caso do "badernaço", tratava-se de "baderneiros, arruaceiros, guerrilheiros" (no documento, os dois últimos termos estão sobrepostos).

Já no registro das declarações do jornalista Fernando Lemos, então editor executivo do Correio Braziliense, constava que o mesmo não tinha avançado nas conclusões acerca da identificação das pessoas envolvidas no "badernaço". Um contraventor do jogo do bicho teria dito que eram agentes da P2 (Setor de Informações do Estado-Maior) as pessoas que comandaram o quebra-quebra. Segundo outra fonte, o núcleo do comando do quebra-quebra pertenceria à "comunidade de informações" e teria vindo da região do Bico do Papagaio, o que dificultaria sua identificação.

0 mesmo jornalista, em depoimento prestado em 23 de dezembro de 1986, trouxe mais indícios à comissão. ${ }^{10}$ Declarou que, depois da troca de informações com órgãos da imprensa, concluiu que os grupos responsáveis pelas depredações e incêndios seriam compostos por pessoas de fora de Brasília. Suas conclusões teriam resultado da observação do estilo de organização de que eram dotados os grupos, da frieza com que agiam e o nível de informações reveladas no curso das depredações. Na opinião do jornalista, o roteiro seguido pelos depredadores parecia previamente traçado, obedecendo a objetivos definidos. Perguntado sobre qual seria a linha política dos "baderneiros", de direita ou de esquerda, Fernando Lemos dizia se tratar de questão complexa. Entretanto, segundo as informações que obtivera, as organizações paramilitares de direita revelavam uma certa organização e se identificavam, às vezes, pela roupa e pelo tipo de calçado (aqui, então, sugerindo uma possível linha de investigação). De acordo com o registro do depoimento, o jornalista julgava, ainda, pouco provável que o 
próprio Governo estivesse envolvido nas depredações, uma vez que esse tipo de tumulto seria potencialmente incontrolável, colocando em risco a estabilidade política.

Se o registro do depoimento for fiel às suas palavras, ele parecia pressupor que a estabilidade política é, de fato e sempre, a meta dos governos - isso, apesar de a conduta da polícia ter lhe causado perplexidade, inclusive dando margem para a suposição de que o "badernaço" havia sido projetado por agentes do Governo. Dizia ainda que, mesmo com algumas pichações com a sigla MAR (Movimento Anarquista Revolucionário), acreditava não se tratar de militantes dessa organização. Sugeria outras possibilidades: grupos vinculados à UDR (no documento não fica claro se se tratava da "união ruralista"), à TFP (Tradição Família e Propriedade) e a uma incerta "Seita Moon". Dizia, também, que não conseguia entender o porquê da dedicação com que a polícia quebrara as máquinas fotográficas dos repórteres presentes no evento.

0 tom da fala dos sindicalistas foi um tanto mais aguerrido, sobretudo no intuito de denunciar as violências policiais cometidas antes do tumulto e afastar qualquer possibilidade das organizações de esquerda serem responsáveis pela manifestação, nas depredações e nos incêndios. Assim, o dirigente da Central Geral dos Trabalhadores, CGT, Antenor Gentil Júnior, ${ }^{11}$ afirmou, entre outras coisas, não conhecer qualquer dirigente sindical com experiência de práticas militares ou técnicas guerrilheiras (o que sugere, ao menos, que ele foi explicitamente perguntado sobre o tema, embora não haja registro da pergunta e nem de seu autor). Ao longo das manifestações, algumas pessoas the teriam parecido estranhas, apresentando as seguintes características:

Jovens com menos de 30 anos, corpos atléticos, corte de cabelo bem feito, calças jeans, tênis, camisas amarelas, pessoas que ficaram muito próximas à polícia e que proferiam palavras de confronto com a polícia; que, no entanto, a polícia não molestava a qualquer desses manifestantes. Que na opinião do depoente os atos de vandalismo foram praticados por grupos de direita ou paramilitares, isto porque o depoente conhece todos os militantes de esquerda de Brasília, digo, grande parte dos militantes, podendo afirmar que esses grupos se orientam pelo caminho pacífico. ${ }^{12}$

Francisco Domingos dos Santos, então presidente da CUT, solicitou que fosse consignado o seu protesto pela presença do secretário de Segurança Pública na comissão de sindicância. Desejava ainda registrar a sua estranheza pelo fato de que a polícia, tão eficiente e brutal na repressão aos manifestantes, não adotara conduta semelhante para cercar e proteger os estabelecimentos da estação rodoviária e do Setor Comercial Sul. Observava, além disso, a demora do Corpo de Bombeiros para chegar aos locais onde ocorriam os incêndios.

Diante de tantas suspeitas e indicações de possíveis linhas de investigação, as teses da comissão de sindicância soam um tanto decepcionantes. ${ }^{13}$ Em suas conclusões, endereçadas 
ao governador do Distrito Federal, a comissão afirmava que o "badernaço" se restringia ao segundo momento de uma manifestação incialmente pacífica. Destacava que a existência de manifestações políticas fazia parte do processo democrático, o qual criara um clima favorável à política, com a população "sem medo, depois de 21 anos de autoritarismo". Do ponto de vista da comissão, os líderes sindicais teriam agido de modo a moderar os momentos de confronto quando a tensão crescia, contendo "os grupos mais radicais que, já no Congresso, pareciam querer iniciar o processo de desordem". Para a comissão, teria se dado a infiltração de um grupo organizado, predisposto a provocar atos de violência. A comissão não identificou, individualmente, nenhum dos depredadores.

(...) Que se tratavam de jovens usando camisas amarelas como marcas de distinção, de porte atlético e atuando com grande mobilidade, dando a impressão de uma ação planejada e comandada; além disto, e mais grave, o grupo dispunha de alguns tipos de artefatos menores, inclusive um maçarico.

Por outro lado, em sua conclusão, a comissão destacava que, até um certo momento, as ações e discursos haviam acontecido dentro "dos limites toleráveis de comportamento democrático ordeiro" - o que incluía a ação repressiva enérgica por parte da polícia que teria se dado, "na maior parte do tempo, dentro dos limites da legalidade, salvo graves fatos específicos de brutalidade". Quanto ao comportamento da polícia, quando as depredações se iniciaram, a comissão registrara não ter encontrado uma explicação convincente, ainda mais diante das denúncias de que, ao mesmo tempo em que depredadores e incendiários agiam livremente, repórteres eram agredidos, tendo suas máquinas fotográficas tomadas e destruídas - não sendo possível, contudo, determinar se tais atos partiam ou não de uma ordem do alto comando.

Mesmo não constando entre suas atribuições, a comissão de sindicância fazia algumas recomendações a partir das conclusões a que não chegara (provavelmente por ser impossível, diante dos propósitos da sua criação e do contexto político que a envolvia, que se chegasse a qualquer conclusão mais concreta). As recomendações tinham como premissa a proposta de que fatos como aqueles nunca mais se repetissem. A primeira se dirigia de modo abstrato à "sociedade brasileira" e ao "Governo", instando-os a não recaírem na "tentação de usar a repressão" - tentação que seria exatamente o desejo daqueles (quem?) que tinham promovido a "baderna". Destaque-se que o termo é forte, carregado de afetividade, de tons morais e mesmo religiosos: a "tentação" da violência antidemocrática. Apontando para o exemplo das manifestações anteriores ao Plano Cruzado II - quando ocorriam atos favoráveis ao Governo, promovidos pelos chamados "fiscais do Sarney", alguns dos quais teriam recaído em 
"exageros", como "saques e ameaças de linchamento"-, a comissão destacava que atos políticos deviam ser considerados necessários, diante do objetivo de se governar com o apoio da população. A segunda recomendação alertava para os riscos da convocação das Forças Armadas para atuar na segurança pública. A terceira, expunha a sensação da fragilidade da democracia no Brasil:

É preciso entender os limites do comportamento democrático. Qualquer gesto que vá além disto, qualquer pedra jogada, qualquer propriedade atacada, qualquer violência física contra indivíduos, significa uma ruptura com o processo democrático e a manifestação perde sua razão, sua justificativa e sua liberdade. Nos próximos meses e anos o Brasil terá que realizar um cuidadoso aprendizado de democracia e passa por ele a prática livre, séria e responsável do direito e da necessidade de manifestação.

Esse aviso não deixa evidenciado, porém, a quem se dirigia essa exortação - que obviamente não podia se limitar ao receptor imediato do relatório, o governador. Observe-se, ainda, na passagem citada, que a defesa da democracia vinha acompanhada pela advertência de que qualquer gesto excessivo (e quem arbitraria quais gestos seriam considerados excessivos? O governo? A "nação"?) implicaria uma ruptura com o processo democrático, acarretando mesmo a perda da liberdade! "Qualquer pedra jogada" tiraria a legitimidade de uma manifestação. Assim, por um lado, o Governo deveria respeitar o direito à manifestação; os manifestantes, por sua vez, deviam limitar suas ações, pautando-se pelo respeito à propriedade e às pessoas; e, por fim, as forças policiais deveriam passar por uma "reciclagem", um processo de modernização democrática.

A questão que se coloca não é, exatamente, uma cobrança extemporânea no sentido de que a comissão fizesse mais do que fez ou escrevesse as recomendações finais com outro tom. 0 discurso vazio das conclusões do relatório interessa, historicamente, como uma espécie de sintoma do mal-estar político do pós-ditadura, de sinal da paralisia e dos limites da chamada "transição democrática". Qualifica-se aqui as conclusões e recomendações vazias, uma vez que elas se pautaram em ideias aprovadas por um vago consenso político e acadêmico, tais como "diálogo", "respeito" e mesmo "democracia". Ideias que, caso separadas de uma prática política efetiva, tornam-se intangíveis no limite da salada de palavras, o que chamamos no cotidiano de "conversa fiada". Mais: palavras vazias dirigidas a interlocutores mal delineados, como a "sociedade" que "precisa aprender a democracia".

Se fortes indícios apontavam para uma atuação de agentes do Estado, acobertados por alguns setores do Governo, como a própria Secretaria de Segurança Pública ou a então moribunda "comunidade de informações", a nulidade da apuração sugere algo mais grave: a continuação da impunidade dos crimes de Estado na democracia. Impunidade, por sua vez, que é um dos indícios mais fortes para o grau de participação do Estado em crimes 
e violações aos direitos humanos, contrapondo-se, sob o selo do silenciamento forçado, disfarçado de silêncio, à dimensão trágica do processo de anistia durante e após a ditadura militar (Greco, 2009).

0 consenso democrático, construído entre o fim dos anos 1970 e o começo dos anos 1980, tinha, entre suas tópicas, a ideia de que, para usar uma expressão de Denise Rollemberg, em texto que trata de tema correlato ao deste artigo, porém mais voltado para a questão da memória das esquerdas, todos resistiram contra a ditadura - todos resistimos (Rollemberg, 2006). 0 reencontro "da sociedade com a democracia criou um fosso entre o passado e o futuro, como se para fazer este fosse preciso esquecer aquele". Nesse fosso, jaziam (jazem?) os espectros do autoritarismo que, com uma frequência considerável, atormentam uma transição democrática com potencial interminável. Esses espectros, porém, não são figuras isentas de realidade - não devemos confundir o seu estatuto impalpável com o da inatividade, como se fossem meras fantasias ou traumas psíquicos. Ao contrário, eles estão encarnados em dispositivos e aparelhos do Estado que sobreviveram à ditadura militar - dos quais temos notícias por meio de silêncios e lacunas. Silêncios sobre os crimes cometidos, silêncios em memórias marcadas pela confusão entre anistia e impunidade e lacunas documentais fruto de um sequestro da História por agentes envolvidos em crimes de Estado. A conclusão de que, no fim deste trabalho, não sabemos quem foram os atores do "badernaço" - apenas contamos com indícios mais ou menos fortes (alguém pode se perguntar: e se fosse mesmo um movimento de guerrilha urbana?) - não implica um beco sem saída historiográfico, porque essa mesma falta de conclusão se torna objeto de reflexão. Por exemplo, se a pensarmos nos termos da espectralidade do passado ditatorial e de suas sobrevivências.

Este texto acaba de ser escrito quando circulam falas de oficiais militares defendendo uma nova "intervenção militar", e analistas que até ontem consideravam impensável, hoje jogam com a possibilidade (ainda que distante) de um novo golpe militar. Acontecendo ou não esse golpe, uma coisa já se sabe, sem necessidade de conjecturas: sua possibilidade nos assombra e, nem que seja como instrumento de chantagem política, essa possibilidade tem efeitos no real. 


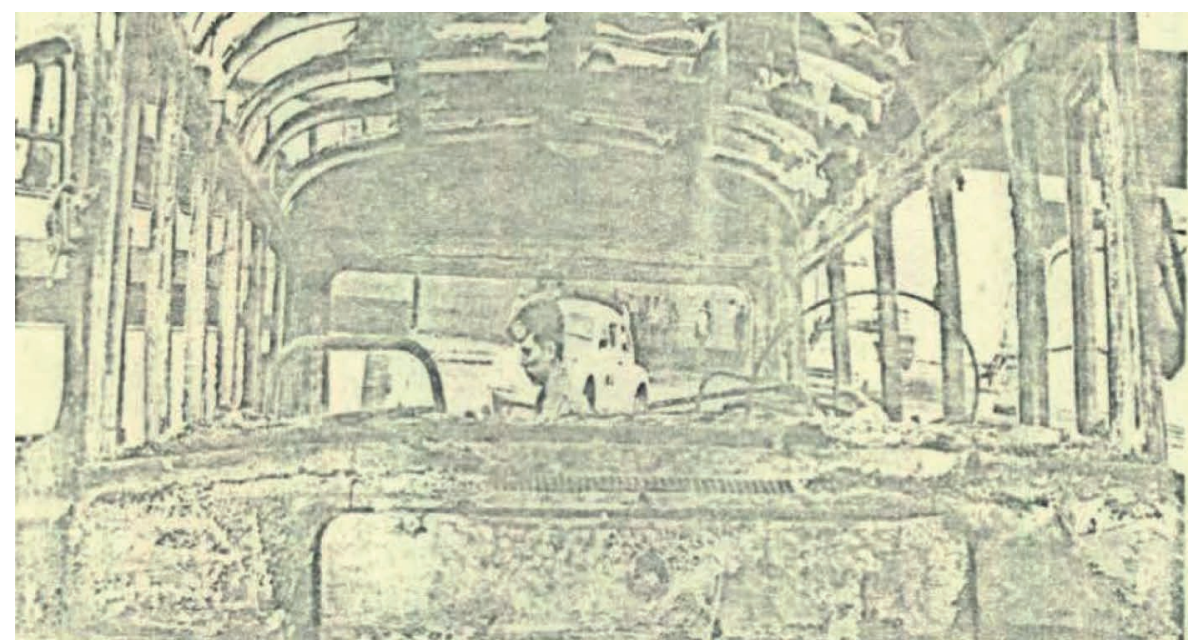

\section{NOTA}

1 Arquivo Público do Distrito Federal, Fundo Secretaria de Segurança Pública, Badernaço 001 (01), p. 1.

2 Idem (05), p. 41.

3 Ibidem p. 4.

4 Correio de Notícias, Curitiba, p. 5 dez. 1986.

5 Jornal do Brasil, Rio de Janeiro, Primeiro Caderno, p. 9., 27 jul. 1988.

6 Consenso não implica, obviamente, unanimidade. Para uma leitura divergente, realizada naqueles mesmos anos, vale a pena consultar o livro Que tipo de república?, de Florestan Fernandes, no qual o cientista social defende a tese da revolução democrática contra o uso propagandístico da etiqueta de "Nova República", ao mesmo tempo que observava que a "transição democrática" vinha se dando a partir de um acordo entre "políticos profissionais" que tinham migrado para o PMDB, a vocação dos liberais aliados à ditadura que tinham Ihe dado um "superego civilizado" e a capacidade de manobra dos principais militares no lidar com a "impotência da burguesia" (Fernandes, 1986: 34).

7 Arquivo Público do Distrito Federal, Fundo Secretaria de Segurança Pública, Badernaço 001.

8 Idem (02), p. 6.

9 Ibidem (05), p. 72.

10 Ibidem (02), p. 23.

11 Ibidem (05), p. 51.

12 lbidem p. 53.

13 Ibidem (06), p. 119-129. 


\section{REFERÊNCIAS BIBLIOGRÁFICAS}

BLANCO, Maria Pilar del; PEEREN, Esther (Ed.). The spectralities reader: ghosts and haunting in contemporary cultural theory. Nova York: Bloomsbury, 2013.

BORGES, Jorge Luís; BIOY CASARES, Adolfo; OCAMPO, Silvina. Antologia de literatura fantástica. São Paulo: Cosac Naif, 2013.

CASTRO, Celso; D'Araújo, Maria Celina. Militares e política na Nova República. Rio de Janeiro: FGV, 2001.

COUTO E SILVA, Golbery do. Conjuntura política nacional: o Poder Executivo e geopolítica do Brasil. Brasília: EdUnB, 1981.

DERRIDA, Jacques. Espectros de Marx: o estado da dívida, o trabalho do luto e a Nova Internacional. Tradução de Anamaria Skinner. Rio de Janeiro: Relume Dumará, 1994.

FARGE, Arlette. Lugares para a história. Trad. Fernando Scheibe. Belo Horizonte: Autêntica, 2011.

FERNANDES, Florestan. Que tipo de república. São Paulo: Brasiliense, 1986.

GRECO, Heloísa Amélia. Anistia anamnese vs anistia amnésia: a dimensão trágica da luta pela anistia. In: SANTOS, Cecília Macdowell; TELES, Edson; TELES, Janaína de Almeida. Desarquivando a ditadura: memória e justiça no Brasil. São Paulo: Aderaldo e Rothschild Editores, 2009. v. 2, p. 524-540.

GREEN, Penny; WARD, Tony. State crime: governments, violence and corruption. Londres: Pluto Press, 2004.

GUILHOT, Nicolas. The democracy makers: human rights and the politics of global order. Nova York: Columbia Univeristy Press, 2005.

JOFFILY, Mariana. 0 aparato repressivo: da arquitetura ao desmantelamento. In: REIS, Daniel Aarão; RIDENTI Marcelo, MOTA; Rodrigo Patto Sá (Org.). A ditadura que mudou o Brasil: 50 anos do golpe de 1964. Rio de Janeiro: Jorge Zahar, 2004.

LAMOUNIER, Bolívar; FARIA, José Eduardo. O futuro da abertura: um debate. São Paulo: Cortez/Idesp, 1981. MARTINS FILHO, João Roberto. A guerra da memória: a ditadura militar nos depoimentos de militantes e militares. Varia Historia, Belo Horizonte, n. 28, p. 178-201, dez. 2002.

MAUAD, Ana Maria. Por uma história fotográfica dos acontecimentos contemporâneos, Rio de Janeiro, 30 de junho de 1987. Revista Tempo e Argumento, Florianópolis, v. 8, n. 17, p. 90-133. jan./abr. 2016.

PRZEWORSKI, Adam. Como e onde se bloqueiam as transições para a democracia? In: MOISÉS, José Álvaro Moisés; GUILHON, J. A. Dilemas da consolidação da democracia. Rio de Janeiro: Paz e Terra, 1989. p. 19-47.

QUADRAT, Samantha Vaz (Org.). Não foi tempo perdido: os anos 80 em debate. Rio de Janeiro: 7Letras, 2014.

ROLLEMBERG, Denise. Esquecimento das memórias. In: MARTINS FILHO, João Roberto (Org.). 0 golpe de 1964 e o regime militar. São Carlos: UFSCar, 2006. p. 81-91. 
SILVA, Francisco Carlos Teixeira da. Crise da ditadura militar e o processo de abertura política no Brasil, 19741985. In: DELGADO, Lucília de Almeida Neves; FERREIRA, Jorge (Org.). O tempo da ditadura militar: regime militar e movimentos sociais em fins do século XX. Rio de Janeiro: Civilização Brasileira, 2007. v. 4, p. 243-281. (Série 0 Brasil Republicano).

ZAVERUCHA, Jorge. Relações civil-militares: o legado autoritário da Constituição brasileira de 1988. In: TELES, Edson; SAFATLE, Vladimir (Org.). O que resta da ditadura: a exceção brasileira. São Paulo: Boitempo, 2010. p. 41-76. 